\title{
Therapeutic Management of Oral Lichen Planus: A Review for the Clinicians
}

\author{
${ }^{1}$ Raghavendra Kini, ${ }^{2}$ DV Nagaratna, ${ }^{3}$ Ankit Saha \\ ${ }^{1}$ Professor, Department of Oral Medicine and Radiology, AJ Institute of Dental Sciences, Mangalore, Karnataka, India \\ ${ }^{2}$ P rofessor, Department of Periodontics, AJ Institute of Dental Sciences, Mangalore, Karnataka, India \\ ${ }^{3}$ Intern, AJ Institute of Dental Sciences, Mangalore, Karnataka, India
}

Correspondence: Raghavendra Kini, Professor, Department of Oral Medicine and Radiology, AJ Institute of Dental Sciences NH 17 Kuntikana, Mangalore-575004, Karnataka, India, Phone: +91-9845822204, e-mail: raghkini@ yahoo.co.in

\section{ABSTRACT}

Lichen planus is a chronic, noninfectious, inflammatory disease of skin and mucous membrane. Intraorally the buccal mucosa, tongue and gingiva are the sites commonly involved. It affects women more often than men in a ratio 3:2. It has well-recognized clinical signs and symptoms, the symptoms may range from none, through mild discomfort to severe burning sensation. In comparison with cutaneous form, the oral lesions are more resistant to therapy and are less likely to undergo spontaneous remission.

Treatment is administered mainly to resolve symptoms and discomfort. Choice of treatment may vary from patient to patient depending on the severity of the lesion and systemic condition of the patient. A variety of agents have been employed to treat oral lichen planus, but corticosteroid remains the mainstay of treatment. However, in the recent past, newer drugs like Tacrolimus have shown promising results. In view of fact that there is a risk of malignant transformation of atrophic and erosive forms of oral lichen planus, the patients need to be actively treated and kept on long-term follow-up. This article highlights various agents used in treatment of oral lichen planus, their mechanism of action, dosage and untoward effects.

Keywords: OLP, Tacrolimus, Corticosteroid, Management of OLP.

\section{INTRODUCTION}

Lichen planus derives its name from similar lace-like pattern produced by symbiotic algae and fungal colonies found on surface of rocks, termed lichens. Lichen planus is a common chronic mucocutaneous disorder, which was first described clinically by Wilson in 1869 and histologically by Dubdreuilh in $1906 .{ }^{1}$ Oral lichen planus is commonly seen on buccal mucosa and vestibular areas followed by lateral borders of tongue and gingiva. The mean age at onset is in 4 th to 5 th decade of life, and common in females. ${ }^{2} \mathrm{~A}$ t least one-third of patients with oral lesions also demonstrate cutaneous lesions. Clinically, it can appear in six different forms- reticular, papular, plaque-like, atrophic, erosive and bullous. ${ }^{3}$

Oral lichen planus (OLP) appears as a hyperkeratotic plaque or striae, and is asymptomatic, except for atrophic, erosive and bullous form, wherein there could be mild discomfort to severe burning sensation. Histopathologically, oral lichen planus shows - focal hyperkeratosis, acanthosis, basal cell liquefaction degeneration and a dense band-like infiltrate of T Iymphocytes. ${ }^{4}$

Although, the etiology of oral lichen planus is not fully elucidated, it is well-documented that oral lichen planus represents a T-cell mediated autoimmune disease in which auto cytotoxic CD 8 cell triggers apoptosis of epithelium. ${ }^{5}$

Antigen presenting cells and basal keratinocytes are activated by antigenic stimulations. A ctivated antigen presenting cells and keratinocytes secrete chemokines that attract the lymphocytes into the developing oral lichen planus lesion.

\section{MANAGEMENT OF ORAL LICHEN PLANUS}

$M$ any patients with oral lichen planus may not have any symptoms, in such cases there may be no need for active treatment except for reassurance and periodic check-ups. However, in many cases patients suffer from painful, erythematous, erosive or bullous lesions which have a slight predilection for transformation into oral squamous cell carcinoma. Thus, the principal aim of treating OL P would be to resolve the painful symptoms, the oral lesions and long-term follow-up to counter the chances of transformation into malignant lesions, especially for erosive and atrophic forms of OLP, which are more prone for transformation. ${ }^{4}$

Oral lichenoid reactions are lesions similar to OLP caused by unmasking of the causative gene of OLP by certain drugs and materials. The best way to treat it is to identify the drug or material causing it and replace it with another drug or material. However, in cases of cardiovascular drugs and epileptic drugs where replacements are not possible, the line of treatment is similar to that of OLP. ${ }^{6}$

A wide variety of therapeutic modalities have been employed to treat oral lichen planus which include corticosteroids, ${ }^{2}$ retinoids and its derivatives, ${ }^{7}$ immunosupressors like cyclosporine, levamisole and azithioprine, ${ }^{8,9}$ antifungal agents like griesofulvin and PUV A therapy. ${ }^{10}$ These agents are either prescribed al one or in combination, the choice purely depends on professional judgment. 


\section{Corticosteroids}

Corticosteroids have been found to be the most predictable and successful agents in treatment of oral lichen planus. They can be used topically, intralesionally or systemically. ${ }^{11}$

The efficacy of corticosteroids for treatment of lichen planus is mainly attributed to its anti-inflammatory and immunosuppressive actions. ${ }^{12}$

Multiple mechanisms are involved in the suppression of inflammation by corticosteroids, they include reduction of the exudation of leukocytes and plasma constituents, thereby lessening edema, maintenance of cellular membrane integrity with the consequent prevention of excessive swelling of the cells, inhibition of lysozyme release from granulocytes, inhibition of phagocytosis, stabilization of the membranes of the intracellular lysozymes, which contain hydrolytic enzymes capable of cell digestion and extension of the inflammatory tissue damage. Corticosteroids also inhibit proliferation of fibroblasts with the positive effect of decreasing fibrosis., 2,12

Topically, corticosteroid therapy is usually the treatment of choice initially, as it can be effectively delivered to the lesion surface with minimal potential for systemic side effects. Some agents used for topical application include $0.05 \%$ flucocinonide, ${ }^{13} 0.05 \%$ clobetasol (Powercort ${ }^{\circledR}{ }^{\circledR}$ cream, Clobenol $^{\circledR}$ cream), ${ }^{14} 0.1$ to $0.2 \%$ triamcinolone acetonide ( $\mathrm{K}$ enacort oral paste ${ }^{\circledR}$, Cortrima $^{\circledR}$ cream), dexamethosone and betamethasone valverate. ${ }^{15}$

They are prescribed as gels, creams, ointment with orabase $\left(\mathrm{K}\right.$ enalog in O rabase ${ }^{\circledR}$ ) or oral rinses. Drugs which are available in orabase formulations are preferred because of their tenacity on the oral mucosa leading to better drug delivery. Triamcinolone acetonide is available in $0.1 \%$ buccal paste form $\left(\right.$ Tess $\left.^{\circledR}\right)$. These agents are either applied topically or rinsed (if in the form of solution) 3-4 times/day after meal. Patients are advised not to eat or drink for 30 minutes thereafter. ${ }^{2}$

Prolonged use of topical steroids over denuded areas may lead to local complications like blanching of the mucosa, hypopigmentation of the applied area, delayed wound healing with increased friability of the mucosa, and often systemic complications like, Cushing's syndrome, reversible H PA - axis suppression, hyperglycemia or glycosuria. This is especially a problem as it is absorbed rapidly in oral mucosa leading to it reaching its tolerable levels within a short span of time.

Intralesional corticosteroids are reserved for cases which do not respond to topical steroids. 10 to $20 \mathrm{mg}$ of insoluble

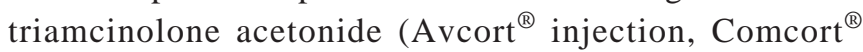
injection) is diluted with $0.5 \mathrm{ml}$ saline or lidocaine $2 \%$ then injected into the lesion, which solubilize gradually and therefore have a prolonged duration of action. M ain drawback of using intralesional corticosteroids being atrophy of tissue, secondary candidiasis (it can be treated with topical antifungal agent like candid mouth paint) and difficulty to deposit sufficient quantities into gingival lesions. ${ }^{11}$

Systemic corticosteroids are indicated for short period for recalcitrant cases that fail to respond to topical steroids.
Prednisone (Wysolone ${ }^{\circledR}$ ) 40 to $80 \mathrm{mg}$ daily for less than 10 days without tapering is advised. The dosage regimens are determined individually based on medical status, severity of disease, and previous treatment response. If underlying medical problems are present, consultation with patient's physician is important.

If corticosteroids are used for prol onged therapy, they should not be stopped abruptly. If done so, it can flare up the underlying disease for which steroids were prescribed and cause acute adrenal insufficiency because of HPA axis suppression.

If supraphysiological doses are given for long time it can lead to electrolyte imbalance, hypertension, hyperglycemia, osteoporosis, increased susceptibility to infections and hirsutism. ${ }^{12,16}$

\section{Retinoids}

Systemic and topical retinoids have been employed to treat OLP. Retinoids include the natural compounds and synthetic derivatives of retinol that exhibit vitamin A activity. Retinoids were synthesized by making minor structural changes. First generation compounds include retinol and compounds derived from it metabolically - tretinoin and isotretinoin. Second generation retinoids are synthetic analogs, which include etretinate and acitretin. Third generation retinoids include arotinoids, which currently are in development. ${ }^{7}$

Retinoids have been noted to have antikeratinizing and immunomodulating effects. A s compared to systemic retinoids, topical retinoids are preferred and generally produce good results.

Systemic retinoids can produce dryness of skin and mucosa, sloughing of skin, rashes, itching, partial hair loss, and may also increase triglyceride and cholesterol levels. In light of such adverse effects, topical preparation is preferred over systemic preparation. ${ }^{13}$

Tretinoin is available in the form of $0.05 \%$ cream (Retino$\mathrm{A}^{\circledR}, \mathrm{Airol}^{\circledR}$ ). Isoretinoin is available as $0.05 \%$ gels ( Sotret $^{\circledR}$, $A\left(\mathrm{CnO}^{\circledR}\right)$.

\section{Cyclosporin}

Cyclosporin is a very commonly used immunosuppressive drug which belongs to a family of cyclicpolypeptides derived from the fungus Tolypocladium inflatum. It is basically used to prevent rejection in organ transplantation. It inhibits chronic inflammatory reactions by inhibiting T-cell activation and proliferation, inhibits lymphokine production and release of interleukin- $2{ }^{8}$

Topical cyclosporin can be used either in the form of mouthwashes or in the form of adhesive base. Patients are advised to swish and spit $5 \mathrm{ml}$ of medication $(100 \mathrm{mg}$ cyclosporin/ml) three times daily for 4 weeks or $0.025 \%$ cyclosporin in an adhesive base to apply four times daily, in some cases systemic cyclosporin has been suggested. ${ }^{13}$

$M$ ajor adverse effects of cyclosporin include renal toxicity, nephrotoxicity, neurotoxicity, hirsutism and gingival 
hyperplasia. The main drawback of using cyclosporin is that the drug is not readily available for topical use and secondly it is expensive. ${ }^{17}$

Cyclosporin is available in $25,50 \mathrm{mg}$ cap (Immusol ${ }^{\circledR}$, Imusporin ${ }^{\circledR}$ ) $100 \mathrm{mg} / \mathrm{ml}$ oily solution ( $\mathrm{K}$ atzung ${ }^{\circledR}$ ) and $100 \mathrm{mg} / \mathrm{ml}$ oral rinse (Sandimmun neoral ${ }^{\circledR}$ ).

\section{Levamisole}

Levamisole was developed in 1966 as an antihelmentic drug, but has immunoregulating properties. M echanism of action of L evamisole has been found to:

1. Restore the normal phagocytic activity of macrophages and neutrophils

2. Immunomodulate or immunopotentiate T-cell mediated immunity

3. Potentiate the activity of human interferon and interleukin-2

4. Inhibit fumarate reductase

5. Inhibit aerobic tumor glycolysis

6. Inhibit mammalian alkal ine phosphatase

7. A Iter the natural course of chronic recurrent inflammatory disease

L evamisole is administered at a dose of $50 \mathrm{mg}$ three times/ day for three consecutive days per week for 4 to 6 weeks. L evamisole (Ergamisol ${ }^{\circledR}$, V ermisol $^{\circledR}$ ) is available as $50 \mathrm{mg}$, $150 \mathrm{mg}$ tab.

A dverse effects include nausea, vomiting, headache and agranulocytosis. $^{18}$

\section{Azathioprine}

A zathioprine is a purine antimetabolite. It has anti-inflammatory properties and decreases antibody production. A zathioprine is reserved for patients who do not respond to other treatment modalities. It can also be used in combination with corticosteroids and cyclosporin. When used in combination with corticosteroids, azathioprine can effectively enhance corticosteroid immunosuppressive activity. Thus, a lower dose of prednisone is required to achieve clinical efficacy and thereby diminishing adverse effects of corticosteroids.

A zathioprine (Imuran ${ }^{\circledR}$, Azoprin $^{\circledR}$ ) is available as $50 \mathrm{mg}$ tab.

It effects rapidly growing cells of bone marrow and GITresulting into leucopenia, thrombocytopenia and GI toxicity. ${ }^{9}$

\section{Tacrolimus}

The use of immunosuppressive agents to treat oral lichen planus is not a new concept. However, the use of tacrolimus is quite recent. Previously used to prevent organ rejection in kidney transplant cases, its topical application in cases of mucosal lesions has been highlighted only in last few years.

Tacrolimus is a macrolide form of immunosuppressant derived from a type of bacterium, Streptomyces tsukubaensis. It inhibits the transcription of interluekin-2 and transduction of signal to T-lymphocyte, and thus effectively causing immuno- suppresion. Its main action can be contributed to its effecive inhibition to calcineurin phosphatase.

Its systemic use is comparable to corticosteroids but topical applications of $0.1 \%$ tacrolimus is proved to be far superior in treating of symptoms of oral lichen planus than $0.05 \%$ cl obetasol. Recent studies by Corrocher et al ${ }^{19}$ have shown that application of tacrolimus ointment $0.1 \%$ four times daily for 4 to 8 weeks resulted in faster resolving of symptoms in oral lichen planus as compared to topical corticosteroid application.

Tacrolimus is available as ointment for topical applications and also as tablets for systemic use. It is available in market in concentration ranging from 0.1 to $0.03 \%$ (Tacroz Forte ${ }^{\circledR}$ ).

A dverse effects of topical application of tacrolimus include burning and itching sensation over the area of application for the first two days of treatment. L ong-term adverse effect of tacrolimus needs to be researched.

\section{Dapsone}

Dapsone should be considered in resistant cases of erosive $O L P$. It has anti-inflammatory and immune-modulatory effects.

It is available as $5 \%$ gel (A cnesone ${ }^{\circledR}$ ) and 25,50 and $100 \mathrm{mg}$ tablets (Dapsone).

Significant adverse effects, such as hemolysis and headache preclude its use. $^{20}$

\section{Interferon}

Topically applied gel preparation containing human fibroblast interferon and interferon-alpha have suggested to improve erosive OLP. Development and exacerbation of OLP during and after IFN-alpha therapy for HCV infection have been reported, al though systemic IF N-alpha (3-10 million IU thrice weekly) is successfully used to treat OLP in patients with and without HCV infection. ${ }^{20}$

It is available as vials (Roferon- ${ }^{\circledR}$ ) and syringes (Intafla-PF ${ }^{\circledR}$ ).

\section{Mycophenolate Mofetil}

It is an immunosuppressant used in treatment of patients with transplants. However, its use in cases of treatment of resistant cases of OLP is also documented. It is a selective inhibitor of purine cycle in lymphocytes. ${ }^{21}$

It is available as 250 and 500 mg tablets (B axmune ${ }^{\circledR}$ ) and $200 \mathrm{mg} / \mathrm{ml}$ suspension (Cellcept ${ }^{\circledR}$ ).

As with other immunosuppressant it reduces the patient's immunity.

\section{Thalidomide}

U se of thalidomide as a recourse to regular line of treatment is not recommended, unl ess all other treatment options have been exhausted. It has been documented to have anti-inflammatory action in cases of auto-immune diseases. ${ }^{22}$ 
Its role in teratogenicity has to be remembered at all times in any case it is to be recommended.

It is available as $100 \mathrm{mg}$ capsules (Oncothal ${ }^{\circledR}$ ).

\section{PUVA Therapy}

Photosensitizing psoralen drug and UV A radiation wasintroduced as a new therapy for oral mucosal lesions in 1987 by J ansen et al.

Psoralens belong to the furocoumarin class of compounds, which are derived from fusion of a furan with a coumarin. Four psoralens are used in PUV A therapy- psoralen, 5 methoxy psoralen (B ergapten ${ }^{\circledR}$ ), 8-methoxypsoralen (M ethoxsalen ${ }^{\circledR}$ ) and 4, 5, 8-trimethyl psoralen (Trioxsalen ${ }^{\circledR}$ ).

Photosensitizing drug can either be administered systemically or applied topically before irradiation. U Itraviolet irradiation in combination with psoral ens modulates the function of the cells of the immune system.

$M$ ajor side effects include nausea, blistering and painful erythema. Patient should be monitored for liver functions, serum creatinine and for cutaneous carcinoma (which can occur 10 times than expected frequency). ${ }^{10}$

\section{NONTHERAPE UTIC OPTIONS}

\section{Photodynamic Therapy}

Photodynamic therapy is a technique that uses a photosensitizing compound activated at a specific wavelength of laser light to destroy the targeted cell via strong oxidizers, which cause cellular damage, membrane lysis and protein inactivation. The exact mechanism of action of PDT is unclear. It would appear to act on hyper proliferating cells with selective uptake of photosensitizers into these cells. It has been suggested that PDT may have immunomodulatory effects and may induce apoptosis. In lichen planus, this may reverse the hyperproliferation and inflammation.
A phenothiazine dye methylene blue was described and attributed to its photodynamic properties. M ethylene blue can be administered topically and orally and it may be a preferred choice for superficial lesions in skin and oral cavity. The fact that methylene blue has a strong absorption at wavel ength longer than $620 \mathrm{~nm}$, where light penetration into tissue is optimal, has led to the use of methylene blue as a promising candidate for PDT. 23

\section{Surgery and Lasers}

Surgical excision, cryotherapy, $\mathrm{CO}_{2}$ laser and ND:Y A G Iaser have all been used in the treatment of OLP. In general, surgery is reserved to remove high-risk dysplastic areas. Excimer $308 \mathrm{~nm}$ laser is an effective choice for treatment of OL P cases as it is well tolerated and painless when used. ${ }^{24}$

\section{CONCLUSION}

Oral lichen planus is chronic mucocutaneous disease of unknown etiology. Patients with erosive or atrophic forms particularly should be observed periodically as it has malignant transformation potential varying between 0.3 to $3 \%$. Continuous devel opment in study of this disease along with its management protocol is required due to recent increase in incidence of squamous cell carcinoma in even non-risk population group. ${ }^{4}$

For the effective management of $O L P$, one has a wide range of drugs to choose from. When a patient with oral lichen planus presents with a burning sensation, usually as a first line of drug therapy one can prescribe a topical preparation of steroid and retinoids. A sa second line of treatmentincases that do notrespond to topical steroids alone, we may prescribe in conjunction with immunomodulatory drugs like L evamisole and Dapsone. It is only in resistant cases, where it is not responding to topical preparations or in severe form of OLP that tacrolimus and systemic corticosteroids in conjunction with immunosuppressive

Table 1: Management of oral lichen planus

\begin{tabular}{|c|c|c|c|}
\hline Asymptomatic & \multicolumn{3}{|c|}{$\begin{array}{l}\text { Periodic check-up, reassurance } \\
\text { Diazepam }\end{array}$} \\
\hline \multirow{6}{*}{ Symptomatic } & $\begin{array}{l}\text { Topical steroids } \\
\text { Topical retinoids }\end{array}$ & & $\begin{array}{l}\text { Good efficacy, proven track record and economical } \\
\text { Of value when combined with topical steroids in conditions of OLP } \\
\text { of gingiva }\end{array}$ \\
\hline & Topical steroids with either & $\begin{array}{l}\text { Levamisole } \\
\text { Dapsone }\end{array}$ & $\begin{array}{l}\text { Used as an immunomodulator } \\
\text { Has anti-inflammatory and immunomodulatory effects and very } \\
\text { useful in cases of resistant OLP }\end{array}$ \\
\hline & & Cyclosporine & Has immunosuppressive properties, expensive \\
\hline & $\begin{array}{l}\text { Intralesional steroids } \\
\text { with or without topical steroids }\end{array}$ & & $\begin{array}{l}\text { Can cause secondary candidiasis and difficult to deposit sufficient } \\
\text { quantities in gingiva }\end{array}$ \\
\hline & $\begin{array}{l}\text { Tacrolimus } \\
\text { Systemic steroids } \\
\text { with or without }\end{array}$ & Azathioprine & $\begin{array}{l}\text { Good results, no long-term follow-up on adverse effects } \\
\text { Use steroids with caution for short-term, azathioprine is used as a } \\
\text { steroid sparring agent }\end{array}$ \\
\hline & Surgery and lasers & & Reserved for high-risk dysplastic areas \\
\hline Lichenoid reaction & \multicolumn{3}{|c|}{ Eliminate causative agent or the drug } \\
\hline
\end{tabular}


like A zathioprine can be employed. So, it is essential to choose appropriate drug, mode of administration and dosage regimens individually and equal importance should be given for stress management. The treatment options have been summarized in Table 1.

\section{ACKNOWLEDGMENT}

We would like to acknowledge the help of Dr A shish Singh, postgraduate student in Department of Oral Medicine and Radiology in preparation of the manuscript.

\section{REFERENCES}

1. Wilson E. Oral lichen planus. J Cutan Med Dis Skin 1869: 117-32.

2. Silverman S J r, Gorsky M , L ozda-N ur F. A prospective study of findings and management in 214 patients with oral lichen planus. Oral Surg Oral M ed Oral Pathol 1991;72:665-70.

3. Andreasen J0. Oral lichen planus. Oral Surg Oral Med Oral Pathol 1968;25:31-41.

4. Rajendran R. Oral lichen planus. J Oral Maxillofac Pathol 2005;9(1):3-5.

5. Eversole LR. Immunopathology of oral mucosal ulcerative, desquamative, and bullous diseases: Selective review of literature. Oral Surg Oral M ed Oral Pathol 1994;77:555-71.

6. Rice PJ, Hamburger J. Oral lichenoid drug eruptions their recognition and management. Dent U pdate 2002;29:442-47.

7. Zagarelli DJ. Treatment of oral lichen planus with topical vitamin A acid. J Oral Pathol 1985;39:186-90.

8. Eiren D rore, Ellis Charles N, Duell Elizabeth A . Effect of topical cyclosporin rinse on oral lichen planus- a double blind study. N Engl J Med 1990;323:290-94.

9. Lozada F. Prednisone and azathioprine in the treatment of patients with vesiculobullous erosive oral disease. O ral Surg Oral Med Oral Pathol 1981;52:257-63.

10. Kuusilehto A, L ehtinen R, Happonen RP, et al. A n open clinical trial of a new mouth-PUVA variant in the treatment of oral lichenoid lesions. Oral Surg Oral Med Oral Pathol 1997;84: 502-05.

11. M ollaoglu N . Oral lichen planus: A review. BrJ Oral M axillofac Surg 2000;38:370-77.
12. Carhere M, Gass E, Carranza M, et al. Systemic and topical corticosteroids treatment of oral lichen planus. J Oral Pathol M ed 2003;32(6):323-29.

13. Buajeeb W, K raivaphan P, Pobrurksa C. Efficacy of topical retinoic acid compared with topical flucinolone acetonide in the treatment of oral lichen planus. Oral Surg Oral M ed Oral Pathol 1994;83:21-25.

14. Lozada-Nur F, M iranda C, Maliksi R. Double-blind clinical trial of $0.05 \%$ clobetsol proprionate ointment in orabase and $0.05 \%$ flucinonide ointment in orobase in the treatment of patients with oral vesiculo erosive diseases. Oral Surg Oral M ed Oral Pathol 1994;77:598-604.

15. Tyldesley WR, Harding S. B etamethosone valerate aerosol in the treatment of oral lichen planus. Br J Dermatol 1997;96: 652-59.

16. Thongprasom K, Dhanuthai $\mathrm{K}$. Steroids in treatment of lichen planus: A review. J Oral Sci 2008;50(4):377-85.

17. V oute $A B E$, Schulten EAJM, et al. Cyclosporin $A$ in an adhesive base for treatment of recalcitrant oral lichen planus. O ral Surg Oral Med Oral Pathol 1994;78:437-41.

18. L u Sy, Chen WJ, Eng HL. Dramatic response to levimisole and low dose prednisolone in 23 patients with oral lichen planus. Oral Surg Oral M ed Oral Pathol 1995;80:705-09.

19. Corrocher G, Di Lorenzo G, M artenelli N, et al. Comparative effect of tacrolimus $0.1 \%$ ointment and clobetasol $0.05 \%$ ointment in patients with oral lichen planus. J Clin Periodontol 2008;35:244-49.

20. Giovanni L odi, et al. Current controversies in oral lichen planus: Report of an international consensus meeting. (Part 2). Clinical management and mal ignant transformation. O ral Surg Oral M ed Oral Pathol Oral Radiol Endod 2005;100:164-78.

21. Dalmau J, Puig L, RoéE, Peramiquel L, Campos $M, A$ lomar $A$. Successful treatment of oral erosive lichen planus with mycophenolate mofetil. J Eur Acad Dermatol Venereol 2007;21(2):259-60.

22. M acario-Barrel $A, B$ alguerie $X$, J oly $P$. Treatment of erosive oral lichen planus with thalidomide (French). Ann Dermatol V enereol 2003;130:1109-12.

23. A ghahosseini F, A rbabitkalati F, Fashtanmi LA , Fatch M, Djavid GE. T reatment of oral lichen planus with photodynamic therapy mediated methylene blue: A case report. M ed Oral Patol Oral Cir Bucal 2006;11:E126-29.

24. M ahnaz Sahebjamee, Fatemeh A rbabi-K alati. M anagement of oral lichen planus. A rch I ranian M ed 2005;8(4):252-56. 